\title{
Lugares e memórias de luzes na cidade de Salvador
}

\author{
Charles d'Almeida Santana*
}

No DECORRER dos ANOS 60 E 70 DO SÉCUlo XX, a grande quantidade de trabalhadores que chegava a Salvador encontrou uma cidade de algum modo convidativa, misteriosa, apertada, festeira. O setor de predominância industrial, concentrado em Itapagipe, acelerava sua decadência. Concomitantemente, toda aquela área perdeu em aporte de recursos públicos na conservação e na atualização de serviços urbanos. Para tanto contribuíram estímulos estatais a empreendimentos produtivos na Região Metropolitana de Salvador (RMS) e de movimentos populares contrários à intensa poluição em toda península. Por força desse desprestígio, expressiva parcela da população transferia-se para outros bairros, particularmente a Pituba, suporte de significativas investidas de urbanização e exploração imobiliária, por muitos considerado a "solução da expansão urbana em Salvador", durante os anos 70 (Tribuna da Babia, 01/10/1976, p. 2).

No mesmo processo, centenas de ônibus passaram a cortar a cidade transportando operários de empresas implantadas em Camaçari, Candeias e Simões Filho, entre outras cidades da RMS. Nas praias, causava espanto o grande número de "desocupados" jogando baba durante os dias de semana, só posteriormente reconhecidos como trabalhadores de turno em tempo de descanso na cidade, cujas vivências urbanas apontam no sentido de uma Salvador cidade-dormitório. Uma

* Professor da Universidade do Estado da Bahia (UNEB) e da Universidade Estadual de Feira de Santana (UEFS) 
condição percebida na perspectiva de que toda dinâmica industrial corresponderia a uma euforia quanto à "modernização" e ao "desenvolvimento", traduzindo uma circunstância na qual se desenhava " $a$ hora e a vez da Bahia" (Ver Espinheira, s.d. É interessante registrar que o autor afirma ainda que "essa sensação é amplamente transmitida à grande massa pelas agências de formação de opinião pública”. Se foi assim, e creio que posso concordar com Espinheira, parece que essa percepção poderia também ter sido apropriada pelos migrantes).

Aos olhos de lavradores migrantes do Recôncavo baiano, surgiam ruas e vielas marcadas por semelhanças com suas origens. Mas assustadoras se visualizadas as diferenças. A extinção dos bondes trazia nova s cores ao coração urbano. Viadutos, túneis e avenidas de vale redimensionavam acessos a bairros próximos ao centro e outros mais distantes, por força “do crescimento do tráfego, cada dia mais congestionado numa cidade de uma rua só, em cada trecho, subdividida em nomes diferentes" (Mensagem do prefeito Heitor Dias, 1963, p. 6). E o crescimento vertical, o acelerado aumento populacional e a expansão das áreas habitadas condicionavam o impacto da chegada de pequenos proprietários rurais, meeiros e rendeiros à capital baiana.

Entre milhares de trabalhadores rurais que chegaram durante esse período, encontramos Antonio Oliveira da Silva, que conheceu a capital por volta de 1967, logo após o término do serviço militar prestado no Tiro de Guerra, na cidade de Cruz das Almas. Veio morar com o irmão mais velho, em um quarto no Calabar, próximo à Avenida Centenário e ao nobre bairro da Graça, abaixo do Cemitério do Campo Santo, subindo o morro do Alto das Pombas. Uma área que inundava mesmo com pequenas precipitações de chuva, encharcando barracos e o quase extinto pântano sobre o qual a população ergueu casas. Nos becos alagados, ruíam improvisadas pontes sobre regos de líquido fétido. As águas da chuva corriam do Calabar até a Ondina, em direção às invasões do Bico de Ferro e do Alto de Ondina, onde mais tarde foi erguido o Bahia Othon Palace Hotel, sua segunda morada na capital da Bahia (Depoimento de Antonio Oliveira da Silva, 25/01/1997).

Suas lembranças das ladeiras enlameadas e escorregadias e das águas das chuvas anunciam "uma situação bastante difícil" para os moradores. Recordações que detonam dúvidas e reticências acerca de seu novo viver, sobre o número de cômodos no Calabar, por exemplo; 
e da certeza hesitante de que no Alto de Ondina sua residência "era um quarto maior, uma casa maior com três cômodos, ou três, não me lembro bem..." Nessas antigas invasões de moradias improvisadas à mercê de inundações, Antonio Oliveira iniciou uma longa e poderosa investida de construção de uma memória da soterópolis, da urbanização de Salvador, de lutas de trabalhadores do campo em busca da criação/recriação de seus lugares na cidade.

\section{Campo e cidade na voz e no corpo}

As recordações registradas na fita dão conta de continuidades do universo de origem como referência central na interpretação do urbano e dimensão comparativa dos problemas e qualidades da cidade. Ainda hoje, Antonio Oliveira considera a importância dos caminhos da roça na sua adaptação ao viver citadino, pois embora tenha migrado com o intuito de trabalhar, a "vida ficou lá, as amizades que a gente deixou lá". Ou, pedaços radicais de sua existência permaneceram quase perdidos, guardados por parentes e vizinhos que se mantiveram no interior do estado.

Talvez uma sensação que não tenha se sustentado após as freqüentes visitas à Cruz da Almas, oportunidades em que participa nas transformações por lá ocorridas. Mas, de todo modo, registra o recurso a experiências ${ }^{1}$ no campo enquanto cria percepções dos estilos de vida urbanos e constrói alternativas de convivência com as luzes da cidade e as ladeiras do Alto de Ondina. Instigantes ocasiões de produção da cidade ao tempo em que o maravilhado Luis Vianna Filho, primeiro governador na ditadura militar, referia-se à "Grande Bahia" compreendida e sentida na confiança e no entusiasmo das iniciativas públicas e privadas (Mensagem do Governador Luis Vianna Filho, de 1968, p. 5). Certamente, uma redução ao nível estadual da propalada bandeira do "Brasil Grande", criada pelos golpistas de 64.

1 Estou me ancorando na definição do termo "experiência" formulada por E. P. Thompson, que significa sentimentos e emoções radicalmente vivenciados historicamente como idéias e como elemento efetivo do presente vivido. Ver Thompson, 1987, p. 9-10 e Thompson, 1981, p. 5. 
Desse ângulo de visão, o "esplendor" da Bahia afloraria visceralmente unido a realizações de trabalhadores rurais distantes de seus lugares de origem. Mas esse estar na cidade matizado pela distância de referenciais persegue os ex-trabalhadores rurais. Durante as entrevistas, a memória e a história fundem campo e cidade sem vacilar. O tempo não vem inscrito enquanto duração cronológica de experiências e vivências numa progressão linear. Mas, é "esse, que ouvimos, tempo represado e cheio de conteúdo, que forma a substância da memória" (Bosi, 1994, p. 422). As falas com as quais lidamos são índices que apontam múltiplas lembranças e esquecimentos dos sujeitos históricos. São pistas que aceitam ser enfrentadas segundo a perspectiva histórica. E abrem possibilidades ao historiador de mergulhar no "tempo contido no instante em que a luz da estrela cadente cintila para uma pessoa" (Benjamin, 1995, p. 129).

As trajetórias urbanas dos migrantes surgem entrecortadas tanto por visitas à roça, quanto por projetos de retorno ao campo limitados principalmente pela impossibilidade de aquisição de uma fazenda, uma vigorosa aspiração existente entre meeiros, rendeiros e pequenos proprietários da região dos depoentes.

De outro ângulo, os vínculos com Salvador mostram-se cada vez mais difíceis de serem rompidos, em vista de fortes relações que vão sendo permanentemente constituídas e reconstituídas com a cidade, desde a conquista de uma carreira profissional de algum modo consolidada, até argumentos enaltecedores da cidade formulados por amigos e familiares. Contudo, a continuidade das considerações memoriais a respeito de qualidades da roça, surgem como resistência à cidade, ao carnaval, ao elevador em grandes prédios, à cidade "volumosa, bastante exagerada, de fazer admirar o número de pessoas, o volume de carro numa avenida. E a expectativa: para onde que todo mundo vai?" Um certo temor a indicar importantes desdobramentos, como que se perguntando: Terei lugar em meio a toda essa instabilidade? ${ }^{2}$

2 Raymond Williams considera que "Há mais em jogo, mais a perder na cidade; ali o equilíbrio é mais precário, e o equilíbrio, maior; os breves momentos de descanso são mais difíceis de perceber; o sucesso e o fracasso manifestam-se sob formas novas e mais problemáticas" (Williams, 1990, p. 303). 
Muitos depoimentos anunciam incertezas semelhantes como reação/subordinação à insistência em educar/controlar/domesticar o corpo e a voz dos migrantes de forma indissociável. Os encontros com meninas interioranas no Campo Grande, por exemplo, faziam-se no sentido de minorar o impacto da adaptação. Namoradas que por vezes faziam-se mestres na arte de viver o urbano, "ensinavam" novas maneiras de lidar com o corte de cabelos, roupas e rebolados em agradáveis noites dançantes. Muito provavelmente, essas meninas, como em outros lugares, esforçavam mais intensamente por sintonizar-se, uma vez que "a vinda para a cidade descortina um outro mundo para um grupo de jovens mulheres... E representa, além disso, a possibilidade de se obter estabilidade familiar-afetiva, enfim a possibilidade de sobreviver" (Neves, 1994, p. 63).

Nas perspectivas de Antonio Oliveira, as recordações do período em que trabalhavam em canteiros de obras dizem muito de "uma amargura muito grande, virando concreto na mão grande", calejando/dilacerando as palmas das mãos, os dedos, desde as sete horas da manhã até já bem avançada a noite, em algumas oportunidades. Aqui, mais do que surpreender uma intensa exigência física ao lidar com cimento, brita, areia, chama a atenção o necessário cuidado com o corpo para admitir novos modos de trabalho, pois afinal os corpos não se mostram passíveis e imutáveis frente a nossas vivências e experiências históricas.

Ao que podemos perceber, enquanto uns necessitavam modificar as maneiras de andar para não passar vergonha tombando nos escorregadios pisos de supermercados, situações difíceis de ocorrer nas feiras do Recôncavo, muitos corpos migrantes vivenciaram uma dolorosa adaptação ao mundo do trabalho urbano. De um ângulo, a perda de um certo domínio do tempo impactou esses trabalhadores, na medida em que significava um controle "externo" da escolha do momento de iniciar, interromper e cessar o trabalho diário. Em outro sentido, aprender a preparar concreto sem o recurso de uma betoneira, demanda exercitar músculos diferentemente de quando se cava a terra para plantar feijão, café, cana-de-açúcar, inhame. Tal particularidade referese tanto à força empregada quanto a evoluções dos corpos em cada um dos trabalhos realizados.

Eis uma dimensão que abre reflexões acerca de variantes do uso de determinadas ferramentas, assim como a importância da adequação 
do corpo na utilização de outras absolutamente desconhecidas no universo rural de origem. Um esforço que indica uma aprendizagem que se processa num corpo vivencial autônomo e, "ao mesmo tempo, ligado de modo inextricável ao seu entorno, com o qual vive em permanente intercâmbio" (Neves, 1994, p. 323). Talvez, a amargura maior tenha sido a aprendizagem para lidar com produtos inexistentes nas roças, a exemplo do cimento. Em alguns depoimentos, os pés e pernas inchados, pois "o cimento estourou meus pés que eu levei três dias de perna pra cima”, indicam a contrariedade que permeou o início do uso de botas na construção civil.

Do ponto de vista de Antonio Oliveira, tratava-se de escolher o como deixar de ser, ou continuar sendo, "um peixe fora d'água":

"No meu caso especificamente, eu não queria também ser diferente. Por exemplo, igual à pessoa que veio do interior há 20 anos, há 15 anos, e com aquele mesmo sutaque, falando as mesmas coisas, falando as coisas da forma que aprendeu lá na roça. Eu não queria ser assim! Eu queria ser menos, eu queria ser mais discreto. Eu não queria ser diferente, como aquelas pessoas que ali estavam. Essa necessidade... e não havia muito como. Porque em cada lugar que a gente chega, as coisas lhe puxam para que você se adapte mesmo. É no trabalho, é na festa, é no baba, é no dominó, no barzinho. Então, você sente que por onde quer que você vá que a coisa é diferente. Então isso vai puxando quer você queira quer não. É um dilema, realmente. Determinado momento, a gente queria mesmo participar. A gente queria ser igual. Mas, algumas coisas não podia fugir das nossas raízes".

Um impasse fundamental, "um dilema, realmente"! Parece que parceiros seus, igualmente oriundos do interior, mas que optaram por manter falares da roça, não se constituíam na imagem futura que Antonio definira para si mesmo. Ele preferiria não ser objeto de "admiração" por parte de soteropolitanos, uma vez que em não sendo "igual", teria menos oportunidade de "participar" e usufruir/construir a cidade. Porém, ao mesmo tempo em que buscava integrar-se à vida urbana o mais rápido e intensamente possível, queria sentir que "tá contribuindo, trazendo também coisa de lá da roça pra cá”. 
Essa reflexão foi suscitada por uma pergunta que formulei, estimulado por palavras suas que se referiam às dificuldades de adaptação: É isso. Como é que você se virou? O complicado processo de adaptação à cidade, que se urbanizava e industrializava, aparece como algo que "vai acontecendo com naturalidade, com o tempo a gente se acostuma". A alternativa consolidava-se, conforme uma dada interpretação, identificando, entre dimensões da vida em Salvador, aquelas que se aproximavam ao interior e aquelas que se diferenciavam, segundo complexos parâmetros comparativos. O jogo de inúmeras possibilidades condicionou-se por uma "necessidade" estabelecida pela escolha de Antonio em "ser igual", em "aprender o sotaque" praticado em Salvador.

De toda sorte, sua percepção aponta uma cidade envolvente que põe pressões múltiplas no sentido de apressar a adaptação dos migrantes. Entre elas, poderíamos destacar a escola da paróquia da Vitória; o mundo do trabalho esforçando-se para que Antonio e seus conterrâneos aceitassem a perda do domínio do que produzia na construção civil; a intercessão da política da ditadura na Bahia, removendo populações para construir a vitrine turística da cidade; a participação de migrantes no "movimento comunitário" em luta por serviços urbanos em bairros de população pobre. Mas ele preferiu, ainda que anuncie o trabalho, sublinhar momentos de lazer: "é na festa, é no baba, é no dominó, no barzinho". Se há quem pense que tenhamos aqui uma insólita rememoração, é por não considerar o peso de espaços lúdicos na elaboração das experiências de trabalhadores. Ao final das contas, são lugares privilegiados na memória da aprendizagem de linguagens urbanas, que não se constituem exclusividade do depoimento de Antonio Oliveira.

Os exageros de Salvador e os assombros correspondentes contribuíram no sentido de não se desfazerem os vínculos com a roça. Nos depoimentos, estão presentes a memória da casa-de-farinha, as lembranças do cuidado com as plantas, as recordações das diferenças com os grandes fazendeiros. Tais presenças adquirem visibilidade principalmente na entrevista de Antonio Pereira de Quadros, um vendedor de confecções aposentado sem nunca ter interrompido sua participação na lida em plantações de fumo e mandioca, nos Municípios de Dom Macedo e Conceição do Almeida. Atualmente, as mãos grossas e calejadas, as pernas levemente feridas por garranchos falam do trabalho em 
sua pequena propriedade rural, da velha casa ainda iluminada por um fifó, rodeada de pés de manga e produtivas jaqueiras.

O corpo por inteiro expressa a necessidade de estar em Dom Macedo Costa, já que Salvador não oferece mais trabalho a pessoas de mais idade. Quando fica parado "dá uma agonia retada": as mãos, as pernas, os braços sofrem de uma ansiedade incontrolável de viajar para o interior, qual uma extemporânea vontade de superar sofrimentos novos através de prazeres esquecidos (Ver Santa'Anna, 1997, p. 276-7). $\mathrm{O}$ orgulho em apresentar os registros corporais da vida com enxada e foice, sugerem um passado ainda de fato presente para Antonio. Caminhar junto a arbustos espinhosos e limpar pastos de plantas rasteiras e espinhosas significa cruzar tempos e espaços, em roças para onde freqüentemente viaja a contragosto da esposa e filhas. Em todo caso, nos faz lembrar reflexões sobre outras ocasiões históricas, nas quais uma trabalhadora rural "aprendeu a viver como uma citadina. Contudo, em cada traço do seu corpo e em muitas de suas atitudes, sobressaía a sua origem campesina" (Hoggart, 1973, p. 30).

Divididos entre o campo e a cidade, ontem e hoje, os migrantes convivem com este dilema crucial. A intensidade com que o interesse no retorno ao campo emerge, varia a depender, sobretudo, do tema tratado na memória, do instante em que é retomado na entrevista. As reflexões acerca do viver urbano igualmente flutuam se considerarmos a interpretação, de cada entrevistado, das transformações nos caminhos do Recôncavo e nas ruas de Salvador por ele vivenciadas. Importa notar o tom da voz de Antonio de Quadros ao afirmar o acerto em ter migrado para Salvador, enquanto declarava os lucros obtidos com o comércio de roupa, nos prédios residenciais que surgiam nos novos bairros. A exaltação do viver soteropolitano é flagrante. De maneira diferenciada, seu testemunho registra um tímido agradecimento à cidade quando discorre sobre atuais aventuras no interior, em um tempo em que diminuíram as oportunidades mais lucrativas em Salvador, a partir dos anos da presidência de José Sarney. Nessas passagens, a cor da voz atribui um intenso brilho aos pés de manga, à jaqueira, ao saudável ambiente campestre.

Todavia, Antonio Pereira não compõe a memória elogiosa do campo apenas quando elabora sua percepção do período em que as chances de ganho se reduziam na cidade adversa (acerca da composição 
da memória, ver Thomson, 1997). Podemos apreender, ao longo de toda narrativa, um imbricamento da apologia do viver campestre com a manutenção da propriedade rural paterna no seio da própria família. Uma realização pouco comum entre os migrantes entrevistados. Em sua expressiva maioria, os testemunhos dão conta de um poderoso processo de expulsão de agricultores do Recôncavo, articulado com a concentração de terras e com a mediação de múltiplas alternativas historicamente vivenciadas.

\section{Luzes de Memórias}

A descontinuidade da posse da terra, no interior da dinâmica de expropriação ocorrida, matiza recordações peculiares do campo e da cidade de muitos migrantes. $\mathrm{Na}$ entrevista de Catarina Cristina, a "beleza" da cidade ofusca quase completamente "aquele silêncio" e "o canto dos pássaros e nada mais", na localidade de Coração de Jesus, Município de Conceição do Almeida, onde Catarina viveu até ter migrado para Salvador. O propósito é declarar uma oposição radical, ao lado de vantagens possíveis:

"Não existia nem Muritibinha. Coração de Jesus era bem pior. Não tinha luz, não tinha alguém passeando na rua. $\mathrm{E}$ dali não tinha luz era bibi gás, candeeiro mesmo. Pra você sair de um lugar daqueles, que tinha festa de ano em ano, e não ter assim, não ter nada, não ter luz, não ter nada disso pra chegar numa capital foi uma grande diferença, em tudo por tudo. No seu conhecimento, nas pessoas que você estava se dando, nos seus passeios também. A gente podia pegar um ônibus de manhã, ia pra praia, meio dia tava em casa. E passeios por ali, andando também, conhecendo a cidade. Saúde, Nazaré, não sei o quê. O centro, sempre o centro da cidade. A gente tava sentindo que você estava saindo de um, sei lá... de um buraco assim muito coisa. É como se sair de um coisa pra ir para um paraíso. Coisa de luzes, de flores, de jardim muito bonito. Podia até não ser, entendeu? Mas a gente achava uma beleza. Foi uma espécie de um aprendizado 
pra gente" (Depoimento de Catarina Cristina Passos Maciel, 10/09/1999).

O esforço em explicar as diferenças entre os dois mundos é iniciado com uma afirmação anunciadora dos lugares que indicam perda de condição de vida. Um, a pequena propriedade produtiva no Coração de Jesus; outro, o lote de terra na Muritibinha, onde seus pais passaram a residir ao perderem a fazendinha: esta melhor do que aquela que, por sua vez, "era bem pior" do que Salvador. As recordações aqui verbalizadas tratam de Coração de Jesus, distrito de origem das famílias de seus pais. Em momentos diferenciados de suas memórias, quando tematizávamos longamente costumes, hábitos e valores de trabalhadores rurais, podemos surpreender nostálgicas referências a Coração de Jesus, sem sequer ter feito menção à perda da propriedade. Mas as lembranças dos primeiros anos na cidade fazem explodir a imagem que talvez não merecesse ser recordada, a "de um, sei lá... de um buraco assim muito coisa", tão traumática foi a entrega da fazenda como pagamento de empréstimos não cobertos pela produção, nas roças de fumo, café e outras mais.

Catarina conheceu a capital da Bahia aos 16 anos aproximadamente, entre 1970 e 1971. Veio a convite da irmã mais velha, Adalice, com o intuito de contribuir nas despesas, uma vez que o salário não cobria o transporte, a alimentação e o aluguel no bairro dos Pernambués. Durante um bom tempo, ainda na primeira metade da década de 1970, ao mudarem para a Baixa dos Sapateiros, moraram em uma pensão nos fundos do Mercado de São Miguel. Logo Catarina conseguiu um emprego como auxiliar de costureira, na rua Coqueiros da Piedade, no centro da cidade, início da caminhada "para ser gente", estudar, relacionar-se com um maior número de pessoas, conhecer lugares diferentes do "buraco" em Coração de Jesus.

E se quisermos saber quais foram as sensações de Catarina nos primeiros dias em Salvador, a resposta aparece rápida: “Bem, a gente sente assim uma coisa estranha porque você não conhece ninguém, você chega assim muito grossa, aquela coisa assim..." Experiências quase impossíveis de serem verbalizadas sem o recurso a múltiplas reticências e expressões que sugerem definições imperfeitas. Em busca de esclarecer tais imprecisões, relacionado-as a particularidades de sua 
linguagem formulada nas roças de Conceição do Almeida, Catarina conclui:

"Isso foi o maior... é... a maior... a coisa mais difícil que eu achei pra me adaptar com o tipo de conversa com pessoas mais ou menos, né?

Eu não sabia ainda verbo nenhum... nada disso... pra mim... da maneira que eu cheguei do interior eu queria, entendeu? E aí foi difícil foi isso. Quer dizer, o que eu lembro. Foi muito difícil...

Não sei, acho que foi isso foi que me abalou... Você vê que eu guardei isso, eu fiquei sempre na lembrança... esse tipo de coisa.

Era como se você chegasse assim no... sei lá desabrochando assim no... coisa meio estranho... que eu não sei explicar direito... Mas foi! Coisa mais difícil foi isso".

As frases continuam carregadas de dúvidas. A voz adquire inúmeras velocidades e alturas, procurando traduzir o sentido denotativo da palavra "grossa". Quando trata de situações vexatórias por que passou, recorda que seria melhor ter desaparecido, repentinamente, antes mesmo de conseguir desabrochar, "desarnar" na cidade. Um momento de emoção, de intensa dramaticidade, vinculado a realizações insistente e gradativamente construídas por Catarina e permanentemente colado na memória. Passagens da narrativa onde podemos apreender o lugar do aprendizado de uma linguagem urbana por uma trabalhadora rural.

Essa conquista de Catarina condicionou e se equipara em importância à formação profissional, quase sintetizando o "fazer-se" do agricultor na cidade. Em muitas lembranças, a construção de possibilidades de linguagem que permitissem uma fluidez nas conversas surge, de algum modo, demarcando distinções entre o lavrador de origem e o profissional pretendido: uma passagem do universo rural ao universo urbano.

De outro ponto de vista, Catarina organiza sua memória pondo em foco as luzes urbanas de modo a comparar a terra perdida com o pequeno quarto na Baixa dos Sapateiros. Uma morada apertada, que no entanto permitia um rápido acesso a conversas com diferentes pessoas, a 
festas. Do Mercado de São Miguel poderiam ampliar seu aprendizado caminhando pelos bairros da Saúde e Nazaré, namorar a arquitetura de casarios e igrejas, criar uma prática de espaços e peculiares geografias segundo aventuras narradas qual relatos de viagens (ver Certeau, 1994. p. 200).

O direito de conhecer as ondas do mar aparece sublinhado. Afinal, uma das curiosidades que mais estimulou Catarina a migrar foram as informações quanto à praia. Ela afirma que "queria ver como era uma praia", e reafirma que "queria ver como era", pois em Conceição do Almeida seu saber limitava-se a fontes, tanques e "rios bem estreitinhos". Essa decisão primeira aponta uma realização pessoal, uma conquista de tal amplitude que carece da confirmação divina: "Meu Deus! Será que eu estou aqui, sou eu mesmo que estou aqui”? Um contentamento contagiante. Para além de condicionamentos e limites estritamente econômicos, a intensa vontade de sentir as ondas do mar passarem por sobre a cabeça incentivou Catarina a deixar Coração de Jesus e criar uma memória enaltecedora da cidade. Memória que, assim como a linguagem, não instala "apenas uma questão de análise e descrição de alinhamento, é uma questão de reconhecer as questões como partes de um processo social que, ao ser vivido, não é apenas processo, mas história ativa, feita de realidades de formação e de luta" (Williams, 1979, p. 209).

Catarina cria uma compreensão da paradisíaca beleza urbana que não deixa de considerar, também, "aquele barulho de ônibus, aquela zoada", no centro de Salvador, em contraste com o silêncio e a cantoria de pássaros, no interior. Porém, o barulho urbano, o cômodo pequeno, o orçamento reduzido abriam as portas de lugares de luzes às recém chegadas. Comentar acerca do belo na cidade correspondia a significativos indicadores no depoimento oral. O surgimento da oportunidade de recordar suas experiências noturnas na cidade iluminada provocou uma acentuada aceleração do ritmo narrativo. Uma alegria incontida arrebata Catarina. Intrigantemente ela agradece por eu ter estimulado lembranças de "aquelas luzes. Uma coisa aí Charles, bom, bom, bom você perguntar". A memória da cidade desnuda uma profunda afetuosidade por suas ruas centrais, como um jardim repleto de flores, ainda que "podia até não ser, entendeu? Mais a gente achava uma beleza", freqüentemente visitado ao cair da noite. 
Um espaço privilegiado eram as lojas na Avenida Sete, particularmente a "Feira dos Tecidos". Por volta das dezoito horas, após o dia de trabalho, Catarina poderia estar a preparar-se para o passeio em vitrines decoradas com "algumas paisagens", poucos manequins e muita roupa em exposição. Entusiasmada, ela seguia de loja em loja, comparando o jogo de "lâmpadas fluorescentes por dentro das lojas que clareava tudo", com a "escuridão tremenda, que não tem luz de jeito nenhum". Ela deliciava-se com o reino da eletricidade, já então banalizada. A noite enfeita-se em cores, como em tantos outros tempos e lugares, pontos de sombra e claridade multiplicam-se denunciando estrelas $^{3}$. Catarina encantava-se com os refletores, os manequins, o colorido das roupas com os quais não tardaria a se acostumar, assim como com outras novidades urbanas.

\section{Lugares da memória}

Com o passar dos anos, seria menor o impacto das diferenças entre o campo e a cidade, no cotidiano dos migrantes do Recôncavo. Antonio Oliveira aprendeu a suportar moradias alagadas, conquistou a profissão de marceneiro junto a novos amigos. Antonio Pereira não mais corre por Salvador com enormes sacolas de roupas e já consegue usar elevador, embora passe a maior parte do tempo na roça, em Dom Macedo Costa. Catarina morou com a irmã na Segunda Etapa do Castelo Branco, um conjunto residencial da URBIS às margens da Estrada Velha do Aeroporto. Após seu casamento passou a residir no Saboeiro, em um outro conjunto residencial, distante do centro, sempre distante das vitrines; mas ainda não realizou o sonho de namorar fogos/luzes espocando por sobre a cidade, numa noite de passagem de ano, no interior de uma escuna a navegar em águas de Todos os Santos.

Enfim, múltiplos espaços os quais os depoentes buscam no sentido de encontrar pontos de partida para suas memórias citadinas, de um tempo em que passaram a perder suas referências rurais: lugares das luzes e da memória. Em seus exercícios de rememoração, ao longo das entrevistas, por vezes emergem evidências de peculiares locais de

3 Sobre esse tema, Marcel Roncayolo escreveu um texto inspirador: "Transfigurações Noturnas na Cidade: o império das luzes artificiais" (1998). 
construção/reconstrução de lembranças. Lugares onde compartilham a criação de um conhecimento acerca do campo e da cidade, confrontando a lida nos quintais de café com o trabalho na construção civil, a relação de meação com a Consolidação das Leis Trabalhistas, as festas de Reis com o carnaval, a claridade da cidade com a escuridão da roça ${ }^{4}$.

$\mathrm{Na}$ fala de Catarina, esse lugar é o pequeno quarto de pensão, na Baixa dos Sapateiros, nos fundos do Mercado de São Miguel. Ao lado, "colado" ao dela e de sua irmã Adalice, ficava o quarto de seus primos Mariá e irmãos menores de idade, há mais tempo residindo em Salvador. Cotidianamente encontravam-se para trocar informações sobre o dia de trabalho, passear no Campo Grande, ir a festas e conversar a respeito de tantas novidades. As experiências de Mariá, que fazia às vezes de responsável pelos irmãos e primas, soam categóricas qual orientação de um guia em territórios onde Catarina "não conhecia nada, não conhecia a vida como era... nada". Suas explicações procuravam alertar quanto aos horários de perigo nas ruas e o como eles deveriam se comportar na cidade hostil.

Antonio Oliveira da Silva, além de registrar criativas conversas com seus parentes, no Calabar e no Alto de Ondina, assinala circunstâncias diferenciadas na socialização das memórias ao término do baba, na vendinha e nas festas em clubes. A essa altura "a gente já passava a ter um companheiro, a ter um amigo" migrante de Cruz das Almas, de Serrinha, de Conceição do Almeida, ou nascido em Salvador, com quem compartilhava saberes sobre o campo ainda presentes em sua memória. No depoimento, Antonio Oliveira cuida mais em apontar diálogos com colegas vindos do interior, aqueles que:

"Às vezes falava com orgulho e até com saudade:

- Você torrou farinha na roça?

- Ah! Meu tempo que eu torrei farinha na roça, que vida boa.

Assim como também falava das dificuldades que passou por lá:

4 Para Marcel Roncayolo, "aos grupos de emigrantes não falta nem coesão social, nem fidelidade a certos valores campesinos"; "Para além da simples transferência dos caracteres rurais, a cidade não elimina as relações primárias, as relações interpessoais...". Ver do autor: "Cidade" (1986). 
- Passei muito por isso e tal.

Às vezes até críticas construtivas. A nível de brincadeiras mesmo. A gozação por perder o ônibus. Por não acertar o ponto e tal" (Antonio Oliveira da Silva, depoimento citado).

O orgulho da origem rural surge imbricado a lembranças carinhosas da luta com a mandioca, sem descartar o trabalho duro no plantio do fumo, nos quintais de café, no transporte de vasilhas de água da fonte até os potes de cerâmica dispostos em algum canto da casa. Igualmente importantes são as passagens do testemunho que tratam da integração coletiva dos migrantes à cidade, por intermédio de ironias que diziam respeito tanto ao autor do gracejo quanto àquele que estaria sendo objeto da zombaria. Ambos vivenciando atropelos nas ruas de Salvador, nos ônibus, na multidão soteropolitana enquanto decidiam silenciosamente o que deveria e não deveria ser mantido na memória.

Aliás, o ambiente de trabalho também se constituiu em um considerável lugar de produção de lembranças: os improvisados galpões de carpintaria onde Antonio Oliveira aprendeu a profissão, as salas de costura de Catarina, os bairros percorridos por Antonio Pereira. Já na trajetória urbana de João Santos Santana, ex-trabalhador rural de Cruz das Almas, a memória do campo inventada na cidade ganha relevo no Colégio Carneiro Ribeiro, na Baixa da Soledade, seu primeiro emprego e morada em Salvador, entre 1958 e 1961.

Neste colégio, João conviveu com tias e primos, diariamente subindo a Ladeira do Canto da Cruz, sob o peso de duas enormes sacolas carregadas de farinha, feijão, frutas, verduras adquiridos na Feira de Água de Menino, para abastecer a dispensa do internato. Por vezes, em suas caminhadas por ruas da cidade, era possível ocorrer conversas com algum dos muitos conterrâneos seus acerca do viver na cidade e sobre o "como era que tava o interior". Temas comuns nas prosas com seus parentes, dentro do colégio, associados a advertências de sua tia quanto a brincadeiras e intimidades com estudantes, mais parecendo aulas de disciplina urbana coladas a dimensões das trilhas das roças (Depoimento de João Santos Santana, 11/09/1999).

Tais vivências matizam as lembranças de João, na medida em que a elas recorre repetidas vezes durante o depoimento, de modo a sublinhar seu domínio da escrita; ou para fundamentar afirmações sobre dolorosas 
passagens de sua vida em Salvador, com o olhar do sapateiro Luís que o conheceu descendo e subindo a Ladeira do Canto da Cruz; ou ainda com objetivo de justificar a facilidade ao conhecer a cidade, "de desarnar depois que comecei a sair com os donos, normalíssimo... tinha estudantes que se dava muito comigo, saía pra festa com os minino...".

A alternativa do freqüente retorno a um lugar de produção social da memória emerge poderosamente na narrativa de Antonio Pereira de Quadros. Os lugares demarcados são uma calçada e um bar, ambos no Jardim Cruzeiro, que desde a sua chegada a Salvador, na década de 1960, passaram a centro de encontros de muitos migrantes de Dom Macedo Costa.

A calçada é carinhosamente tratada como "pau de anum" e "pau de galinheiro". A narrativa é longa e entusiasmada:

"Quando não tinha cobrança quase pra fazer, que chegava cedo. Meio dia em diante a gente chegava ali e ficava sentado no passeio alto, antes de asfaltar a rua que era de barro. Ochem! Juntava mais de trinta, aqui na casa de meu cunhado. Trinta pessoas: parente, irmão, sobrinho, cunhado. Juntava um pau de galinheiro danado. Tinha um bar de um parente nosso ali, às vezes a gente vinha praí tomar cachaça, tomar cerveja e jogava palitinho. Todo mundo, todo mundo: Dom Macedo Costa, Almeida conversando coisa passada na roça, o que o outro fazia. Contando os casos daqui da Bahia, que a gente vinha da roça de um jeito que a gente se perdia aí, os fora que os cara davam. Tem dia que a gente chega ali ainda conversa tanta coisa passada. Fica recordando. Pau de anum. Conversava sobre coisa de roça, sobre a rua, sobre freguês que deixou de pagar, se mudou" (Antonio Pereira de Quadros, depoimento citado).

Ao longo de toda entrevista, ele fala do grande número de parentes, vizinhos e amigos do lugar de origem, com quem conviveu na cidade: aquele que facilitou sua vinda para Salvador, estimulando-o; outro que o auxiliou na resolução de questões relativas à moradia; outro que o introduziu no negócio com confecções - todos com quem conversava sobre o campo e a cidade. 
Tanto no "pau de anum" quanto no bar de um parente, conversavam acerca do passado e do presente, elaborando/reelaborando aquilo que poderia ser lembrado ou esquecido, em privilegiadas ocasiões nas quais elegiam e selecionavam os conteúdos das memórias segundo intenções conscientes ou não. As memórias, então, eclodem como "paisagens e imagens que são verdadeiros campos de significado para o lembrado" (Maluf, 1995, p. 70). Nelas ocorrem as peculiares negociações coletivas cujo resultado constitui-se em vigorosos espaços que ainda hoje oportunizam momentos quando recriam recordações sobre a roça e a rua. São igualmente lembrados diversos contratempos no antigo comércio de roupas nos bairros e as dificuldades de adaptação no mundo urbano, aos modos de ser da própria cidade, criando uma "cidade ilegal", "clandestina", dentro da "cidade legal", "cidadã", implantada nos anos da ditadura militar no Brasil (Rolnik, s.d., p. 225-6). Em algumas passagens do testemunho, ainda que não tenha referido-se explicitamente ao pau de galinheiro ou ao bar, onde jogavam palitinho, o tom e o ritmo eram os mesmos de quando os casos narrados localizavam-se nesses espaços.

A percepção dos motivos da grande quantidade de migrantes de Conceição do Almeida e Dom Macedo Costa é um exemplo a destacar: foi "a lei trabalhista. A lei trabalhista vem desgraçando esse país", promovendo a expulsão do meeiro/rendeiro/diarista, nas zonas rurais da região, e a demissão do assalariado, na cidade. Se considerarmos a CLT o motivo da expulsão dos lavradores escolhido por eles nas calçadas do Jardim Cruzeiro, o tempo e o espaço são definidos na origem da migração: as décadas de 60 e 70, em Dom Macedo Costa. Ao refletir acerca de um outro momento e lugar, os anos da presidência de José Sarney em diante, em todo território nacional, a compreensão elaborada sincroniza campo e cidade sem pestanejar, manifestando experiências que não descolam os dois mundos, embora sejam percebidos enquanto diferentes.

Em suas rememorações, outras tantas dimensões do concomitante viver a roça e o urbano são definidas como aquelas que deveriam ser mantidas e amadurecidas, na memória criada nesses importantes espaços de sociabilidade: negociações de imóveis, as condições da rua do pau de anum, as indecisões em migrar, as dificuldades nos primeiros anos em Salvador, o estafante descer e subir escadas em altos prédios, 
por conta do medo de usar elevador. Ou, ainda, incompreensões quanto ao funcionamento de aparelhos elétricos próprios à urbanidade, indicando vivências que tratam de processos de adequação à realidade citadina. Por vezes, os diálogos surgem matizados por uma forma cômica que anuncia resistências ao desconhecido, fundamentadas num específico universo de costumes, hábitos e valores do campo (ver Chaui, 1993, p. 72-4, quando discorre acerca da relação da comédia com a resistência no interior de culturas populares).

Mas são resistências que não traduzem uma negação, e sim uma procura em torno de uma alternativa para aprender a conviver com a geladeira, o fogão a gás, o supermercado. Portanto, é de se pensar que os níveis de dificuldades são tratados com o intuito de criar maneiras diferenciadas de incorporação do novo, ao mesmo tempo em que rearticulam dimensões da cidade e de tradições rurais, como que compreendendo que "há mais em jogo, e mais a perder na cidade; ali o equilíbrio é mais precário, e o perigo, maior; os breves momentos de descanso são mais difíceis de perceber; o sucesso e o fracasso manifestam-se sob formas novas e mais problemáticas" (Williams, 1990, p. 303). A rua, a calçada e o bar são escolhidos como lugares da intimidade, extensões da casa, mais parecendo salas de visita coletivamente definidas. O espaço tendencialmente público é reelaborado como espaço privado e pleno de vozes de trabalhadores do campo (Chauí, 1993, p. 137)5.

O destaque dessas conversas torna-se mais evidente quando afirma que se realizavam cotidianamente, muitas vezes durante cinco horas ao dia. Aos domingos poderiam ocorrer por mais tempo, períodos necessários para a realização do acordo tácito sobre fatos e significados a serem objeto de suas recordações, aquilo que fica e o que não fica, com a presença de trinta ou mais pessoas. Diálogos em territórios que guardam exclusividade aos migrantes de Dom Macedo Costa e Conceição do Almeida: a calçada e o bar. Lugares urbanos apropriados por trabalhadores rurais ao criarem suas experiências enquanto conteúdo de recordações que rastreamos em significativos escaninhos de lembranças iluminadas por ruas, becos, ladeiras, calçadas, bares e vitrines da Salvador de migrantes.

5 Em importante reflexão a respeito do significado da casa e da rua, dialogando com Roberto da Matta, a autora considera um específico movimento de resistência o "criar uma outra rua", no interior da cultura popular brasileira. 
São, enfim, lugares, luzes e memórias que falam de projetos perseguidos em trajetórias citadinas de trabalhadores rurais. Tendo realizado ou não essas pretensões, participaram como sujeitos históricos ativos na produção de territórios na capital baiana. Em todo esse processo, elaboraram específicas formas de viver inscritas nas memórias de lutas na e pela cidade, nos cantos de rua, nos bares, nas brigas, nas prosas: outras e vigorosas estruturas de sentimentos vão emergindo ao longo dos depoimentos que tratam da criação de novas formas de sociabilidades soteropolitanas. Percebemos outras cidades, de um certo ângulo, "cidades invisíveis" em uma Salvador cindida, curiosa, excitante, para além de restritivas visões substantivamente divulgadas nos meios de comunicação de massa. Criações do urbano fincadas na percepção de que "as vantagens da 'marcha do progresso' pareciam sempre beneficiar a outra pessoa" (Thompson, 1987, p. 89); ativas invenções de Salvador em festas e na morte, no trabalho e nas luzes ofuscantes das igrejas do Bonfim, de São Francisco, da Piedade.

As alternativas vivenciadas sugerem considerações acerca de culturas urbanas em Salvador distantes de "grandes temas" que matizam o período. Poderíamos chamar de marginais; mas tal palavra carrega um valor de depreciação, de subalternidade inapropriado. Penso em criativas e ativas intervenções que, de uma maneira ou de outra, desconsideravam regras e possibilidades entendidas por muitos como predominantes e definidoras de comportamentos e valores típicos de uma baianidade turística abrangente ${ }^{6}$. Ao que tudo indica, tal descaso quanto a essa tipificação não significa um desconhecimento sistemático e intencional. Conforme podemos apreender, ocorreram opções de afastamentos, aproximações e alterações de significados em diversos ângulos, como estratégias de sobrevivência e adaptação à realidade urbana.

No jogo citadino sob pressões, condicionamentos e limites específicos, eles inventaram uma Bahia diferente da "Grande Bahia" declarada, e talvez não procurada, pelo então governador Luis Viana. Suas

6 Maria Brandão, em matéria publicada no Jornal A Tarde de 17/9/2000, Caderno 2 , p. 1, lembra que a partir dos anos 80 , "quando o turismo entra na pauta governamental do Estado, tem-se um novo fenômeno que é a baianidade como mercadoria. A Bahia do amor, da solidariedade, é fabricada, e é isso que se apresenta para o mundo". 
experiências da acelerada urbanização-industrialização-racionalização da cidade dizem mais de lutas realizadas do que de vantagens da vida urbana. Para a grande maioria dos entrevistados, a industrialização da Região Metropolitana passou ao largo de seus cotidianos. A via educacional propugnada por políticos de variadas matrizes não foi por muitos trilhada. E apesar de não terem atentado, veementemente, para projetos e arbitrariedades da ditadura, conseguiram conquistar a capital do Estado "aos trancos e barrancos": enfrentando policiais nas invasões, transgredindo o urbanismo "humanizador" e o racionalismo de temporalidades urbanas.

Tanto a cidade quanto o campo surgem como dois lugares da memória que passaram por profundas transformações vivenciadas pelo mesmo sujeito histórico e que detonam rememorações radicais. São difusas comparações que podem indicar o urbano como o lugar de trabalho, enquanto torna-se escasso nas roças. Complicadas inter-relações do cansativo viver citadino com a liberdade campestre. Memórias que sugerem sínteses possíveis da história recente do Recôncavo baiano e de Salvador, navegando entre as boiadas e as pastagens que substituíram o canavial, os quintais de café, as plantações de fumo; percorrendo novidades veiculadas no rádio e na televisão, invasores das casas remanescentes de meeiros e rendeiros, em ambientes de antigas conversas e festas inscritas em um universo de tradições orais do lugar. Lembranças que, por outro lado, tratam de ônibus urbanos, de grandes conjuntos residenciais, da maré dominando os Alagados, da construção de Avenidas de Vale, da multidão e das luzes da urbanidade. Recordações que descortinam o mar revolto no campo e na cidade.

\section{Referências bibliográficas}

BENJAMIN, Walter. Charles Baudelaire, um lírico no auge do capitalismo. São Paulo, Brasiliense, 1995.

BOSI, Ecléa. Memória e Sociedade: lembranças de velhos. São Paulo, Cia. das Letras, 1994.

CERTEAU, Michel de. A Invenção do Cotidiano, 1: Artes de fazer. Petrópolis, Vozes, 1994.

CHAUI, Marilena. Conformismo e Resistência: aspectos da cultura popular no Brasil. São Paulo, Ed. Brasiliense, 1993. 
DIÓGENES, Glória. "Inscrição sobre o Corpo: violência e mitologia". In: Cadernos de Subjetividade. Vol. 5, n. 2. Programa de Estudos Pós-Graduados em Psicologia Clínica da PUC-SP/Núcleo de Estudos e Pesquisas da Subjetividade, $2^{\circ}$ sem/1997, p. 353-70.

ESPINHEIRA, Gey. "Urbanização Segregada - a expansão de Salvador". In: Debates CENPES Ano 2, n. 6, p. 311-17.

HOGGART, Richard. As Utilizações da Cultura. Lisboa, Editorial Presença, 1973. MALUF, Marina. Ruídos da Memória. São Paulo, Siciliano, 1995.

NAJMANOVICH, Denise. "O Sujeito Encarnado: limites, devir e incompletude". In: Cadernos de Subjetividade. Vol. 5, n. 2. Programa de Estudos Pós-Graduados em Psicologia Clínica da PUC-SP/Núcleo de Estudos e Pesquisas da Subjetividade, $2^{\circ}$ Semestre de 1997, p. 309-28.

NEVES, Magda de Almeida. Trabalho e Cidadania: as trabalhadoras de Contagem. Petrópolis, Ed. Vozes, 1994.

ROLNIK, Raquel. "A Cidade dos Saberes". In: Fernandes, Ana (org.). Anais da $3^{\circ}$ Semana de Urbanismo.

RONCAYOLO, Marcel "Cidade". In: Região. Enciclopédia Einaudi. Lisboa, Imprensa Nacional-Casa da Moeda, 1986, vol. 8.

. "Transfigurações Noturnas na Cidade: o império das luzes artificiais". In: Projeto História. Revista do Programa de Estudos Pós-Graduados em História e do Departamento de História da PUC-SP. São Paulo, n. 18, maio/1998.

SANTA'ANNA, Denise. "O Corpo entre Antigas Referências e novos Desafios". In: Cadernos de Subjetividade. Vol. 5, n. 2. Programa de Estudos PósGraduados em Psicologia Clínica da PUC-SP/Núcleo de Estudos e Pesquisa da Subjetividade, $2^{\circ} \mathrm{sem} / 1997$.

SANTANA, Charles. Fartura e Ventura Camponesas: trabalho, cotidiano e migrações: Bahia 1950-1980. São Paulo, Annablume, 1998.

THOMPSON, E. P. A Miséria da Teoria. Rio de Janeiro, Editora Zahar, 1981.

- A Formação da Classe Operária Inglesa: A Árvore da Liberdade. Rio de Janeiro, Paz e Terra, 1987.

THOMSON, Alistair. "Recompondo a Memória: questões sobre a relação entre a história oral e as memórias". In: Projeto História: Revista do Programa de Estudos Pós-Graduados em História e do Departamento de História da PUC-SP. N. 15, abril/97

WILLIAMS, Raymond. Marxismo e Literatura na História e na Literatura. Rio de Janeiro, Zahar, 1979.

- O Campo e a Cidade na História e na Literatura. São Paulo, Cia das Letras, 1990. 
Resumo: Os trabalhadores rurais do Recôncavo Baiano que migraram para Salvador, nos anos 60 e 70, criaram memórias acerca da cidade, segundo possíveis referências a roças de café, fumo, mandioca. Suas recordações indicam espaços urbanos centrais na elaboração das lembranças. São lugares que imprimem luzes a evidências memoriais do urbano, cruzando o tempo da cidade com o do campo. As cores luminosas das vitrines detonam rememorações da falta de conforto, no interior do estado. As dificuldades para conseguir emprego e adaptar-se à realidade soteropolitana surgem enfrentadas pelos depoentes com a alternativa do retorno à Cruz das Almas, Conceição do Almeida ou São Felipe. Lugares que continuam iluminando as percepções do passado de antigos pequenos proprietário rurais, meeiros e rendeiros enquanto elaboram/reelaboram maneiras de viver em Salvador.

Palavras-chave: História e Cidade; Migrantes em Salvador; Espaços Sociais da Memória; Memórias Urbanas.

Places and lights of Memories from Salvador City

ABstract: The inland workers from Recôncavo Baiano who moved to Salvador, during the 60 s and 70 s, created memories about the city, according to possible references to coffee plantations, tobacco, manioc. Their past memories indicate central urban spaces in the elaboration of memories. The bright colors of the windows bring about recalls of lack of confort in the interior of the state. The difficulties in getting a job and adapt to the Salvador's reality comes up faced by the answerers with the alternative to go back to Cruz das Almas, Conceição do Almeida or São Felipe. Places which are still lighting the past perceptions of small ancient farmers and the persons who use the land and are not officially landowners, while they elaborate and re-elaborate the ways of living in Salvador.

KEYWORDS: History of City; Migrants in Salvador; Social Spaces of Memory; Urban Memories. 